\title{
LEGISLAÇÃO AMBIENTAL, DESENVOLVIMENTO RURAL E PRÁTICAS AGRÍCOLAS
}

\author{
ENVIRONMENTAL LEGISLATION, RURAL DEVELOPMENT AND FAMILY FARMING
}

\author{
Pedro Selvino Neumann ${ }^{1}$ Carlos Loch ${ }^{2}$
}

\section{RESUMO}

\begin{abstract}
A questão ambiental é, sem dúvida, o "fato do momento" na civilização humana contemporânea e, provavelmente, o de maior potencial de questionamento $e$ transformação na trajetória do processo civilizatório. Se, por um lado, ela introduz a possibilidade de redirecionar os rumos do desenvolvimento em beneficio das gerações futuras, por outro, os mecanismos concebidos para se alcançar tal objetivo podem trazer sérios problemas à sobrevivência das gerações atuais de agricultores familiares. No caso brasileiro, os instrumentos de gestão ambiental pública são, na essência e de fato, compostos por instrumentos de comando e controle, ou seja, por regras e padrões a serem seguidos, atribuindo penalidades aos que não as cumprirem. Este fato, paradoxalmente, tem reflexos danosos para o desenvolvimento global da sociedade, em particular ao meio rural, uma vez que agrava ainda mais a já precária situação de sobrevivência de grande parcela dos agricultores familiares do país, por onerar o processo produtivo agrícola e por não propiciar os elementos básicos que permitam ao público envolvido o cumprimento das obrigações. O presente trabalho é uma análise dos instrumentos públicos de gestão ambiental brasileira à luz de estudos empíricos, dois deles ocorridos na região central do Rio Grande do Sul, e outro na mata atlântica, no litoral norte do Paraná. A análise dessa problemática é feita a partir dos seguintes eixos: os reflexos da aplicação de uma legislação rígida, que atinge linearmente todo o rural; a desconsideração dos efeitos da coibição de determinadas práticas para a reprodução econômica e social dos agricultores; $e$ as incongruências teóricas e práticas da legislação ambiental.
\end{abstract}

Palavras-chave: legislação ambiental; agricultura familiar; meio ambiente.

\section{SUMMARY}

The environmental question is the moment topic of contemporary human civilization and, probably, that with the greatest potential for questioning and transformation in the trajectory of the civilizing process. If, on one hand, it introduces the possibility of redirecting the path of development for the benefit of future generations, the mechanisms conceived for reaching such an objective can, on the other hand, bring serious problems for the survival of the current generation of family farmers. In the Brazilian case, the instruments of public environmental management are the essence of the subject, composed of command instruments and control or, in other words, rules and standards to be followed, imposing penalties on those who do not comply with them. Paradoxically, this fact has damaging repercussions for the global development of society. In particular, for the rural element, since it aggravates even more the already precarious situation of survival for a large portion of the family farmers in the southern region of the Country. Burdening the agricultural productive process and not providing the basic elements that permit the public involved fulfilling its obligations are stronger reasons. The present work is an analysis of the public instruments of Brazilian environmental management in light of empirical studies, two of them occurring in the central region of Rio Grande do Sul state and one in the forest area of the northern coast of Parana state. The analysis of this problematic question is made from the following starting points: the repercussions from the application of a rigid legislation that reaches all agriculture linearly, ignoring effects of restraint by certain practices on the economic and social reproduction of farmers; and theoretical and practical incongruities of environmental legislation.

Key words: environmental legislation; family farming; environment.

\section{PROBLEMATIZANDO A QUESTÃO}

Os instrumentos de política ambiental, contemporaneamente empregados no mundo são, de duas ordens: Instrumentos Regulatórios, do tipo

\footnotetext{
${ }^{1}$ Engenheiro Agrônomo, Mestre, Professor Assistente do Departamento de Educação Agrícola e Extensão Rural, Centro de Ciências Rurais, Universidade Federal de Santa Maria, 97105-900, Santa Maria-RS. E-mail: psneuman@ccr.ufsmc.br. Autor para correspondência

${ }^{2}$ Professor Titular da Universidade Federal de Santa Catarina. 
Comando e Controle; e os Instrumentos de Incentivos Econômicos ou de Mercado (SOUZA, 1998). O primeiro grupo corresponde àquelas políticas que visam identificar problemas ambientais específicos. As regulamentações formam um conjunto de normas, regras, procedimentos e padrões que devem ser obedecidas pelos agentes econômicos e sociais com vistas a se adequarem a determinadas metas ambientais, acompanhadas de um conjunto de penalidades previstas para aqueles que não as cumprirem. São exemplos de instrumentos de regulamentação as licenças, padrões e zoneamentos.

O segundo grupo de políticas aproveita o vínculo positivo entre desenvolvimento e ambiente, corrigindo ou prevenindo falhas, aumentando o acesso a recursos e tecnologias e promovendo um aumento eqüitativo da renda. Como instrumentos de incentivos econômicos, podem ser citadas as taxas, subsídios, rotulagem, seguro ambiental. São também chamadas na literatura de "políticas win-win", políticas ambientais que propõem, ao mesmo tempo, melhorias ambientais e econômicas. O exemplo seria o subsídio aos procedimentos ou atividades agrícolas sustentáveis, ou ainda a redução de incentivos dados a atividades agrícolas que têm impacto negativo no meio ambiente. Geralmente, são políticas que estimulam a eficiência produtiva na relação insumoproduto, bem como a utilização de tecnologias limpas que geram menos resíduos e menor consumo de matérias primas.

No caso brasileiro, apesar de a Política Nacional de Meio Ambiente (Lei 6.938 /81) prever três categorias de instrumentos de gestão ambiental pública (Instrumentos Regulatórios e Punitivos; Instrumentos de Mercado ou Incentivos Econômicos; e Instrumentos de Informação), ela é, na essência e de fato, composta por instrumentos de comando e controle, ou seja, por regras e padrões a serem seguidos, atribuindo penalidades aos que não as cumprirem. Esta situação é reflexo do fato da gestão ambiental, em nosso país, estar associada à idéia de meio ambiente como um bem público, o qual somente pode ser resguardado eficientemente através de uma incisiva intervenção normativa e reguladora do Estado (BRESSAN et al., 1998). Os defensores desse enfoque confiam excessivamente na capacidade do Estado em exercer os mecanismos de comando e controle.

Além disso, a legislação ambiental no Brasil foi elaborada de modo autocrático, sem que se tomassem as precauções de socialização do conhecimento e geração de alternativas que permitam gestar as mudanças necessárias. Isso resulta em conflito com as práticas agrícolas de grande parcela de agricultores familiares localizados em áreas ecologicamente sensíveis, como é o caso da maior parte do contingente de agricultores familiares do sul do país.

$O$ fato de a gestão ambiental estar baseada essencialmente nos mecanismos fiscalizatórios e coibitivos, paradoxalmente, tem reflexos danosos para o desenvolvimento global da sociedade, em particular no meio rural. Agrava ainda mais a já precária situação de sobrevivência de grande parcela dos agricultores familiares do sul no país, por onerar o processo produtivo agrícola e por não propiciar os elementos básicos que permitam ao público envolvido o cumprimento das obrigações. $\mathrm{O}$ presente artigo pretende analisar os instrumentos públicos de gestão ambiental brasileira à luz de estudos empíricos, dois deles ocorridos na região central do Rio Grande do Sul a, b, e um, na mata atlântica, no litoral norte do Paraná ${ }^{\mathrm{c}}$.

A discussão da problemática será feita a partir dos seguintes eixos de reflexão: os efeitos da aplicação de uma legislação rígida, que atinge linearmente todo o rural e todas as unidades de produção; a desconsideração dos reflexos da coibição de determinadas práticas para a reprodução econômica e social dos agricultores (não fornece as alternativas); e as incongruências teóricas e práticas da legislação ambiental (a indução de práticas, que paradoxalmente aumentam a degradação ambiental).

\section{A RIGIDEZ E LINEARIDADE DA LEGISLAÇÃO AMBIENTAL}

A legislação ambiental brasileira apresenta normas e regulamentações padronizadas que se aplicam linearmente a toda realidade rural. Tal proposição tem como pressuposto a concepção de um espaço homogêneo e, como tal, podem ser propostas soluções e normas padronizadas. Os reflexos dessa questão serão analisados sob três aspectos: a existência de condições ecológicas muito diferenciadas; as características polifuncionais do rural; e a existência de um mosaico de unidades de produção agropecuárias muito diferenciadas entre si.

\section{As condições ecológicas diferenciadas:}

Todo problema ambiental traz uma alta relação com as características ecológicas particulares do local onde ele ocorre. Sendo assim, as soluções propostas, necessariamente, deveriam preservar o vínculo com estas condições ecológicas particulares. $\mathrm{Na}$ verdade, o rural se caracteriza justamente por apresentar características ecológicas espaciais muito distintas, sendo que determinada solução pode apresentar resultados completamente diversos quando variam essas características, o que torna impossível propor soluções ambientais padronizadas. 
Para ilustrar a questão levantada, basta citar a obrigatoriedade, através do Código Florestal (Federal e Estadual), de todas as propriedades possuírem uma área mínima de cobertura florestal (20 a 50\%). A aplicação de tal lei no Rio Grande do Sul se constitui em uma verdadeira heresia ecológica. Desconsideram-se os conhecimentos elementares de fitogeografia, ou seja, que mais de $60 \%$ do território gaúcho apresenta cobertura natural de campo, com suas variantes fitofisionômicas, condições em que as árvores não são os elementos dominantes (BRESSAN et al., 1998).

\section{O rural polifuncional.}

A legislação ambiental brasileira está construída na concepção do espaço rural associado e confundido com a atividade agrícola. Entretanto, as transformações do espaço agrário contemporâneo têm se caracterizado pelo transbordamento do urbano sobre o rural. O resultado de tal processo é a radical diferenciação da população, sendo cada vez maior o número de pessoas ocupadas em atividades não-agrícolas. Assim, a tradicional vinculação mecânica entre o rural e a atividade agrícola torna-se pouco esclarecedora (SILVA, 1999). Na atualidade, como bem demonstra a realidade do município de Santa Maria, expressa na figura 1, o espaço rural assume múltiplas funções como lazer, turismo, residência para trabalhadores urbanos ou prestadores de serviço, comércio e indústria.

O rural transformou-se radicalmente, daí a pertinência da referência a espaços rurais, pois existe uma gama de estruturas agrárias e níveis tecnológicos, evocando formas de agriculturas das mais primitivas, até aquelas ligadas às modernas técnicas do mundo contemporâneo. A noção de rural deveria ser estritamente territorial ou espacial, não podendo ser identificada como um setor de atividades (SARACENO, 1997). As transformações ocorridas implicam que as políticas e os instrumentos de gestão ambiental considerem o fato de que as zonas rurais têm necessidades novas, típicas dos modernos espaços urbanos, como por exemplo, de estabelecer zoneamento para definir áreas industriais e de moradia, áreas de preservação ambiental, além das áreas exclusivamente agrícolas e pecuárias.

Na perspectiva ambiental, o zoneamento no meio rural pode, entre outras questões, auxiliar na localização de uma indústria, que pode ter um potencial poluidor muito diferente, dependendo de sua localização (por exemplo, acima de uma barragem de abastecimento); na definição de taxas de poluição segundo a localização da unidade de produção ou da atividade (determinada taxa de poluição pode ter efeitos diferentes, dependendo da

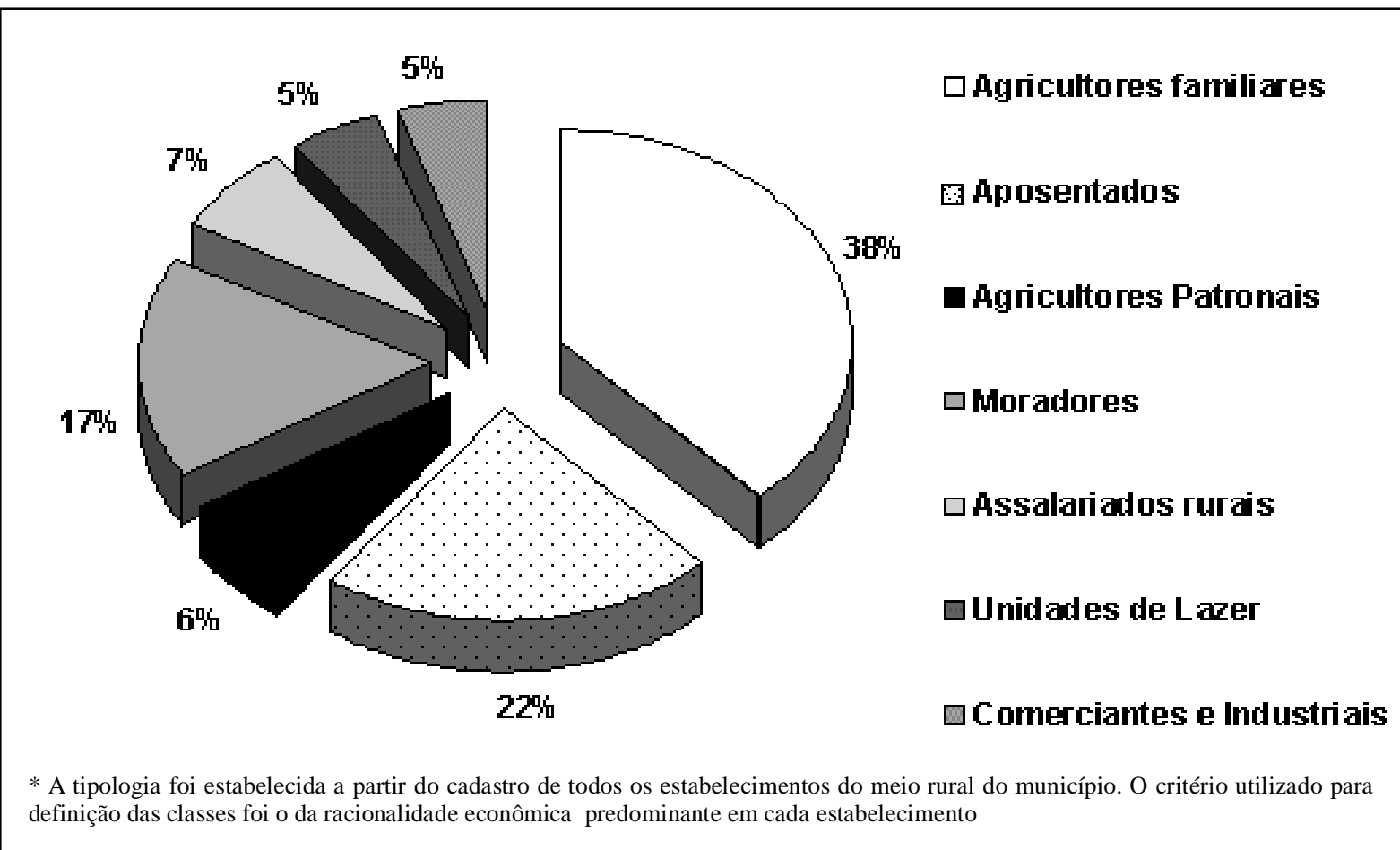

Figura 1 - Classes dos estabelecimentos rurais de Santa Maria.

Ciência Rural, v. 32, n. 2, 2002. 
localização da unidade poluidora); ou, para facilitar a infra-estrutura e a localização de determinados empreendimentos públicos; ou, ainda, orientar a localização das diferentes atividades agrícolas conforme a aptidão do solo.

\section{Unidades de produção diferenciadas:}

$\mathrm{O}$ fato de os agricultores serem minoritários em alguns espaços rurais, como no caso de Santa Maria, não os impede de serem majoritários na ocupação desses espaços e, portanto, terem uma responsabilidade específica na sua gestão. Entretanto, eles só poderão realizar plenamente a gestão de tal espaço, em sintonia com preceitos da sustentabilidade, se os instrumentos de gestão considerarem as particularidades dos diferentes sistemas de produção praticados por esses agricultores. Na verdade, o rural é composto por um mosaico muito diferenciado de unidades de produção, que torna a clássica divisão entre pequenos, médios e grandes produtores inócua para a elaboração dos instrumentos de gestão do espaço rural. A obrigatoriedade de uma área coberta com mata tem impacto muito diferente entre os diversos sistemas de produção; assim também, a taxação da água (Lei das Águas, № 9.433/1997) terá impacto diferenciados nos diversos sistemas que têm como base a atividade de arroz.

A noção de "sustentabilidade" postula que a construção dos diferentes mecanismos de gestão e desenvolvimento ocorra através de situações específicas da realidade, como forma de produzir "respostas" adequadas às condições singulares. Neste sentido, é necessária a tomada de consciência de que grande parte dos problemas da gestão ambiental decorre de um conhecimento insuficiente das condições e modalidades de produção existentes, bem como da conseqüente inadequação dos mecanismos e instrumentos de gestão propostos aos agricultores.

\section{A DISTRIBUIÇÃO DOS CUSTOS DE REDUÇÃO DA DEGRADAÇÃO AMBIENTAL}

A adoção de determinadas normas e regras pode trazer eficácia ambiental objetivando o bem estar de gerações futuras, mas, ao mesmo tempo, pode comprometer a viabilidade econômica de gerações atuais de pequenos produtores rurais. No sul do país, uma grande parcela das pequenas propriedades familiares se concentra nas escarpas das serras, as quais foram recortadas em colônias que abrigam os imigrantes italianos e alemães. É justamente sobre essas áreas que incide a maior carga de instrumentos coibitivos: o Código Florestal
(Federal e Estadual) e as Áreas de Proteção Permanente, a Mata Atlântica, Áreas Tombadas e de Reserva, Estações Ecológicas, Áreas de Interesse Ecológico, Áreas de Proteção Ambiental, Parques Nacionais, Estaduais e Municipais, etc. Para estes agricultores, a legislação ambiental é mais uma tarefa a ser cumprida que traz prejuízos a sua atividade.

Os depoimentos a seguir, de agricultores que se localizam no rebordo da serra de Santa Maria, afetados, principalmente, pelo Código Florestal (Estadual e Federal), ilustram bem a questão. Expressam a insatisfação com a proibição dos desmatamentos (as roçadas de capoirões) e das queimadas. Tais medidas têm implicação direta na técnica de pousio, prática agrícola ainda em uso na maioria dos sistemas de produção praticados na região. A prática de pousio é uma técnica da agricultura itinerante, que consiste em deixar determinada área, após alguns anos de cultivo, em "descanso" por um período relativamente longo (que pode variar de 5 a 15 anos). É uma técnica de reposição de fertilidade, de controle de inços e de controle da fitossanidade, sendo que essa última é muito importante para determinadas culturas suscetíveis a doenças, como é o caso da batatinha inglesa, cultivada pelos agricultores em questão, os quais não visualizam alternativas que venham a substituir as antigas práticas de roçar/queimar. Os depoimentos foram extraídos do estudo "Os Usos da Terra em Unidades de Produção Familiares" realizado por DALMORA (1994).

"O problema de poucas terras não dá para parar de plantar e se segue a orientação do IBAMA tem que desistir da agricultura(...). A gente não é contra a ecologia, mas também assim fica difícil, não se tem mais onde produzir". (A V)

"Onde a terra é fácil, plana, há razão na lei, deve sobrar um mato, um capão. Não que eu seja contra as leis, eu acho que elas tem uma certa função (...), sou a favor da lei onde é terra plana, não precise queimar, o trator vira tudo em baixo". (A. A Linha 6 Norte)

"Embora muitas vezes, professores líderes, pais, comunidades lutem, ficar no meio rural já é muito difícil: o pequeno e grande agricultor não pode mais fazer uma lavoura ( roçar é proibido) não compensa mais os gastos. O IBAMA está sempre supervisionando". (Sinopse da Reunião de Camponeses realizada em junho de 1994).

Assim, em nome de objetivos mais amplos, como garantir a vida das gerações futuras, de garantir um meio ambiente saudável em benefício da humanidade, gerações atuais de indivíduos têm aviltadas as suas estratégias de sobrevivência. Na 
verdade, o que se discute com esta abordagem é a distribuição dos custos da redução da degradação ambiental. Serão os agricultores realmente culpados pela degradação ambiental que seus processos produtivos ocasionam? Existem realmente culpados nessa questão? A legislação não está infligindo um dano a esses agricultores?

Existem soluções técnicas que poderiam ser propostas aos agricultores que desenvolvem as suas atividades em áreas frágeis? A preservação ambiental nessas áreas é possível somente mediante o abandono das atividades agrícolas? $\mathrm{Na}$ verdade, as instituições responsáveis pela criação de alternativas técnicas (instituições de pesquisa) ressentem-se da falta de estudos específicos sobre os sistemas de produção e práticas agrícolas desenvolvidas pelos agricultores dessas regiões. Até mesmo a tão visada prática de reprodução da fertilidade através do sistema de cultivo de queimada foi objeto de poucos e recentes estudos. Essa lacuna decorre da pouca importância que é dada à agricultura dessas regiões, que apresentam uma topografia acidentada, dificultando o desenvolvimento da "moderna" agricultura preconizada pela Revolução Verde.

$\mathrm{O}$ fato de os agricultores preservarem os recursos ambientais, as paisagens, de não poluírem e de conservarem as águas, para que a sociedade tenha hoje e nas gerações futuras uma maior qualidade de vida, não se constitui um serviço prestado à sociedade? Não seria o caso de a sociedade pagar pelo serviço de tomar uma água pura, de consumir alimentos sadios, de usufruir as belas paisagens rupestres? Não se justificariam, assim, o subsídio a esses agricultores como instrumento econômico legítimo perante a sociedade?

\section{EFEITOS PERVERSOS E INCONGRUÊNCIAS DA LEGISLAÇÃO AMBIENTAL}

As estratégias adotadas pelos agricultores para contornar a legislação e compensar os prejuízos econômicos se revelam quase sempre ainda mais danosas. Na discussão do assunto será analisada a questão das restrições ao desmatamento no litoral norte do Estado do Paraná, e o problema das cobranças das taxas pelo uso da água (Lei das Águas) pelos produtores de arroz no Rio Grande do Sul.

Segundo MIGUEL \& ZANONI (1998), os agricultores do Litoral Norte do Paraná, frente às restrições em relação ao desmatamento, através das medidas como autorizações obrigatórias, a proibição de desmatar as margens dos cursos da água as encostas de montanhas e planícies aluviais, passaram a efetuar o desflorestamento clandestino. $\mathrm{O}$ desmatamento clandestino é uma estratégia que permite a manutenção da superfície agrícola útil das propriedades agrícolas. No entanto, as parcelas escolhidas para serem desarborizadas são preferencialmente aquelas que apresentam um difícil acesso, conseqüentemente, uma vegetação arbórea desenvolvida e que não dispõem de boas condições de plantio (grande declividade). Do ponto de vista ambiental, essa situação resulta em uma aceleração do processo de degradação do ecossistema, em razão do desflorestamento indiscriminado e da erosão nestas áreas ecologicamente mais sensíveis. Em nível de estabelecimento agrícola, o cultivo dessas parcelas clandestinas, situadas longe das habitações e estradas, traduz-se em aumento do trabalho e de sua penosidade. Além disso, a demora nos trâmites burocráticos e os atrasos das autorizações para os desmatamentos (roçadas) ocasionam transtornos ao calendário agrícola. No sistema de cultivo de queimada, qualquer atraso no período de desmatamento ocasiona um aumento dos riscos: quanto mais próximo ao período estival ocorrer, maiores as possibilidades de não poder realizar o plantio.

Os estudos no Paraná também demonstraram que a restrição ao desmatamento resultou em uma queda dos rendimentos agrícolas, pois a redução do pousio implica a necessidade crescente de mão-de-obra para capina, a queda significativa dos rendimentos físicos $\mathrm{e}$, da produtividade do trabalho.

$\mathrm{Na}$ verdade, o resultado final das restrições à prática de desmatamento na região abordada foi a diminuição dos rendimentos econômicos dos pequenos agricultores e, muitas vezes, o aumento da degradação ambiental. A floresta representa, para estes agricultores, um "estorvo" à prática econômica.

Em relação à taxação das águas, utilizada no cultivo do arroz no RS, conseqüência da aplicação da Lei das Águas, as principais críticas são sobre a forma como ela foi implantada - sem discussão e tempo para assimilar as propostas (principalmente as taxas) - e não acerca de sua concepção, uma vez que a lei é flexível e descentraliza a gestão. Além das questões relativas à implantação da lei, existem outras duas particularidades na legislação estadual vigente, passíveis de crítica.

Uma primeira questão diz respeito ao aspecto distributivo da aplicação da lei, uma vez que permite economia de escala nos processos de tarifação e licenciamento, beneficiando os grandes empreendimentos, os quais acabam obtendo um custo menor por unidade. A segunda questão - a 
mais grave - diz respeito a uma incoerência da própria lei, O princípio da taxação deveria funcionar como mecanismo econômico para a melhoria da eficiência no uso da água, com a conseqüente redução do consumo de água por unidade de área ou produto. Na prática, porém, a sua aplicação não discrimina níveis de eficiência nem sistemas de produção que tenham demandas diferentes de água, mas apenas a área irrigada. Entretanto, o consumo de água na produção de arroz pode ser reduzido drasticamente com técnicas já amplamente conhecidas para a cultura, como: a sistematização da área para lâminas de água de 0,6 metros; o cultivo em áreas propícias, a captação de água de pequenos riachos nos períodos chuvosos para depósito (ZAFFARONI \& TAVARES, 2000).

Com o uso de técnicas adequadas, a eficiência da irrigação por submersão pode atingir valores em torno de $60 \%$. A eficiência média alcançada pelos agricultores atinge 40 a $45 \%$, podendo, em alguns casos ficar, abaixo dos $30 \%$. Isso implica um consumo de água que é o dobro do que poderia ser alcançado com atendimento às recomendações técnicas para a cultura (GOMES \& PETRINI, 1996).

Assim, por não diferenciar níveis de eficiência de consumo de água, a taxação não possui eficácia ambiental, servindo apenas para onerar mais ainda o processo produtivo.

\section{RECOLOCANDO O PROBLEMA}

Para se criar um ambiente político/institucional favorável à sustentabilidade, é necessário que sejam revistas uma série de pressupostos que dão suporte aos instrumentos e mecanismos da gestão ambiental brasileira, principalmente quanto ao predomínio dos instrumentos regulatórios, do tipo comando e controle. São instrumentos muito rígidos, atingem linearmente todas as unidades de produção, e só serão eficazes se, além da capacidade de estabelecer regras, o governo tiver boa estrutura de policiamento e punição para com aqueles que descumprirem as normas, o que parece não ser o caso brasileiro.

Neste contexto, vem crescendo nos últimos anos, no mundo inteiro, o apoio às políticas de incentivos econômicos, que têm por objetivo principal suprir a falta de flexibilidade econômica dos instrumentos regulatórios, bem como a dificuldade de implantação e fiscalização dos mesmos. Desta forma, eles passam a ser utilizados cada vez mais como complemento aos instrumentos de controle e comando.

O fator fundamental para que a produção agrícola continue crescendo, sem que com isto se tenha que sacrificar o meio ambiente, é a possibilidade de se reduzir a quantidade do impacto no ambiente por unidade de produto, ou por unidade de atividade, mais do que proporcionalmente o aumento da atividade agrícola. Na verdade, somente políticas que introduzam maior eficiência ambiental nas atividades econômicas podem assegurar a compatibilidade entre o crescimento econômico e a sustentabilidade ambiental.

Entretanto, tal questão nos coloca diante da mudança de espírito nos instrumentos de gestão ambiental brasileiros, baseados nas restrições de usos dos recursos naturais e no Direito Negativo, para uma lógica de intervenções planejadas (BRESSAN et al., 1998). Isso servirá também para que a efetividade da gestão ambiental possa ser avaliada mais pelo número de benefícios usufruídos por toda sociedade e menos pelo número de atuações e multas aplicadas. Para que os recursos naturais tenham realmente um significado de "recurso" e não de "estorvo", como é o caso das florestas, para grande parcela dos agricultores familiares.

A questão ambiental não pode se resumir a expressões como "é proibido", "é vedado", "não é permitido", "sanções penais", "auto de prisão"; mas deve postular a construção de conhecimentos, através de situações específicas da realidade, como forma de produzir intervenções humanas adequadas às condições singulares. Neste sentido, cresce a tomada de consciência de que muitos dos problemas dos instrumentos de gestão ambiental empregados, decorrem de um conhecimento insuficiente das condições e modalidades de produção existentes, bem como da conseqüente inadequação das alternativas propostas aos agricultores.

A configuração de um desenvolvimento sustentável aponta para a necessidade de se criar mecanismos e instrumentos de gestão ambiental, que sejam capazes de dar respostas aos problemas colocados, em sintonia com o contexto social, econômico e agroecológico onde estes se manifestam, e adequados às diferentes categorias e atores sociais presentes no rural. Colocar em prática este conceito, como diria SACHS (1998), significa recriar os instrumentos de gestão. Necessita-se, assim, de um sistema de gestão ambiental estratégico, que, apoiado em um conhecimento rigoroso do espaço de intervenção, seja flexível, dialógico, que funcione por meio da negociação e que viabilize o estabelecimento de contratos entre todos os atores envolvidos no processo.

Finalmente, cabe destacar que a posição aqui defendida foi a da complementaridade entre as medidas de regulação e de controle e as políticas de 
incentivos econômicos para o meio rural. Afinal, essas últimas não são a solução para todos os problemas ambientais, principalmente, nos casos que envolvam um risco iminente ao meio ambiente ou à saúde, para as quais não se pode dar ao mercado o poder de escolher.

\section{FONTES DE AQUISIÇÃO}

a "Os usos da terra em unidades de produção familiar". Dissertação de Eliane Dalmora, apresentada ao Curso de Pósgraduação em Extensão Rural, Universidade Federal de Santa Maria, em 1994

b "Enfoque sistêmico e desenvolvimento regional: a experiência da Universidade Federal de Santa Maria”. Pesquisa desenvolvida por Pedro Selvino Neumann, Paulo Roberto da Silveira e Marcos Froelich na região de Santa Maria.

c "Práticas agroflorestais, políticas públicas e meio ambiente: o caso do litoral norte do Paraná", pesquisa desenvolvida por Louvais. A. Miguel e Magda M. Zanoni, Paraná, 1998.

\section{REFERÊNCIAS BIBLIOGRÁFICAS}

BRESSAN, D., MARCHIORI, J.N.C., DURLO, M. O espírito das leis florestais. Ciência \& Ambiente, Santa Maria, v.17, p.89-93, 1998.

DALMORA, E. Os usos da terra em unidades de produção familiar. Santa Maria, 1994. 230p. Dissertação (Mestrado em Extensão Rural) - Curso de Pós-graduação em Extensão Rural, Universidade Federal de Santa Maria, 1994.
GOMES, A. da S., PETRINI, J.A. Manejo de agua em arroz irrigado. In: MAGALHAES JUNIOR, A.M., FAGUNDES, P.R.R. Agricultura real: arroz irrigado. Pelotas : EMBRAPA-CPACT, 1996. p.44-53.

MIGUEL, L.A., ZANONI, M.M. Práticas agroflorestais, políticas públicas e meio ambiente: o caso do litoral norte do Paraná. Revista de Extensão Rural, Santa Maria, v.V, n.5, p.9-23, 1998 .

SACHS, I. Do crescimento econômico ao ecodesenvolvimento. In: VIEIRA, P.F; et al. (ORG), Desenvolvimento sustentável e meio ambiente no Brasil: a contribuição de Ignacy Sachs. Porto Alegre : Pallotti; Florianópolis : APED, 1998. p.161-180.

SARACENO, E. Conceito de ruralidade: problema de definição em escala Européia. Tradução de Angela Kageyama, 1997. Capturado em 22 de set. 2000. Online. Disponível na Internet http://www.eco.unicamp.br/ indexie.html

SILVA, J.G. O Novo rural brasileiro. Instituto de Economia. São Paulo : UNICAMP, 1999. 153p.

SOUZA, R. S. Economia política do meio ambiente. Pelotas : Educat, 1998. 162p.

ZAFFARON E., TAVARES , V.E. O Licenciamento Ambiental dos Produtores de Arroz Irrigado no Rio Grande do Sul, Brasil. Capturado em 23 de set. de 2000. Online. Disponível na Internet http://www.ambiental.net/agroverde. 